\title{
Comparison of the Changes in Corneal Biomechanical Properties after Photorefractive Keratectomy and Laser in Situ Keratomileusis Using Ocular Response Analyzer
}

\author{
HATEM M. MAREY, M.D.; OSAMA A. AL-MORSI, M.D. and ISLAM N. EL-DARAWY, M.Sc. \\ The Department of Ophthalmology, Faculty of Medicine, Menoufia University, Menoufia, Egypt
}

\begin{abstract}
Background: Correction of vision using Photorefractive Keratectomy (PRK) or Laser In Situ Keratomileusis (LASIK) flap creation associated with ablation produces profound changes in the corneal structure and biomechanical properties secondary to central thinning and disruption of collagen lamellar continuity.
\end{abstract}

Aim of Work: This study aims to compare the changes in corneal biomechanical properties after PRK and LASIK in the treatment of low and moderate myopia by Ocular Response Analyzer.

Subjects and Methods: This study included 42 adult eyes divided into two groups: (1) Contain 21 eyes referred for Lasik surgery. (2) Contain 21 eyes referred for PRK surgery. Ocular Response Analyzer (ORA) was applied to each group to measure Corneal Hysteresis $(\mathrm{CH})$ and Corneal Resistance Factor (CRF).

Results: There was no statistically significant difference in $\mathrm{CH}$ and $\mathrm{CRF}$, and between CCT and RSB between the two studied groups. There was statistically significant decrease in $\mathrm{CH}$ after both LASIK and PRK. There was statistically significant decrease in CRF after both LASIK and PRK. There was statistically significant difference in SE after LASIK and PRK. There was statistically significant difference between LASIK and PRK in CH and CRF change with more decrease after LASIK.

Conclusion: PRK and LASIK substantially weaken the biomechanical strength of the cornea, depending on the amount of archived myopic correction, and that the changes in corneal biomechanics were larger after LASIK than after PRK.

Key Words: Corneal biomechanics - PRK - LASIK - Corneal ectasia-Ocular response analyzer.

\section{Introduction}

LASER-Assisted in Situ Keratomileusis (LASIK) and Photorefractive Keratectomy (PRK) are primary procedures for correction of refractive error.

Correspondence to: Dr. Hatem M. Marey, The Department of Ophthalmology, Faculty of Medicine, Menoufia University, Menoufia, Egypt
However, both procedures affect corneal biomechanical properties and may cause corneal ectasia, a post-operative complication [1]

The ocular response analyzer (ORA; Reichert Ophthalmic Instruments, Buffalo, NY, USA) measures corneal biomechanical properties in vivo. A puff of air indents the cornea, and an infrared beam measures the waveform during inward and outward deviations of the cornea. Two properties reported by the ORA are Corneal Hysteresis $(\mathrm{CH})$ and Corneal Resistance Factor (CRF) [2].

$\mathrm{CH}$ is the difference between the inward and outward applanation pressures and reflects the rigidity and elasticity of the cornea. CRF is calculated by multiplying the pressure at which the cornea returns to its original shape by an empirically derived constant and subtracting this value from the pressure required to indent the cornea. CRF correlates more strongly with Central Corneal Thickness (CCT) than $\mathrm{CH}$ [3] . Thin corneas are associated with lower $\mathrm{CH}$ and $\mathrm{CRF}$ values [4]

Several studies have shown that refractive photoablation procedures decrease $\mathrm{CH}$ and $\mathrm{CRF}$, but the stability of these biomechanical properties in the post-operative period has not been well established [5]. No previous study has compared PRK with and without Mitomycin C (MMC) to determine the effect of MMC on $\mathrm{CH}$ and $\mathrm{CRF}$ [6]

Here, the present study evaluated the effect of LASIK and PRK on corneal biomechanical properties and assess the factors that impact preoperative and post-operative $\mathrm{CH}$ and $\mathrm{CRF}$.

\section{Subjects and Methods}

The study was designed as a prospective randomized controlled study. The study was carried 
out in Menoufia University Hospital with collaboration of Alfath Ophthalmology Hospital, Zagazig, Sharkia during 2017 on patients requires correction of vision by Lasik or PRK. Approval was asked from Faculty of Medicine, Menoufia University.

\section{Sample size:}

The study subjects included 42 eyes and informed consent obtained from each person. They were divided into the two groups: Group (I): Contain 21 eyes referred for Lasik surgery. Group (II): Contain 21 eyes referred for PRK surgery.

Inclusion criteria: All patients had fulfilled the following inclusion criteria:

- Age range 20-45 years.

- Spherical equivalent ( $-2 \mathrm{D}$ to $-6 \mathrm{D})$.

- Residual stromal bed $<300$

- Corneal Hysteresis $(\mathrm{CH})$ and Corneal Resistance Factor (CRF) will be measured with Ocular Response Analyzer before and 1 month after surgery.

\section{Exclusion criteria:}

- Patients with Keratoconus, corneal opacities, corneal degenerations and corneal dystrophies.

- Patients with history of previous refractive surgery, ocular trauma or intraocular surgery.

- Glaucomatous patients.

- Patients with posterior segment disorders.

- Patients with Amblyopia.

History:

- Personal history including: Name, age, residence, and telephone number.

- Visual history and progression.

- Medical history of hypertension or diabetes mellitus.

- Family history of similar conditions.

- History of allergy to any medication.

\section{Visual assessment:}

- Evaluation of the best corrected visual acuity.

- Manifest refraction using the autorefractometer.

- Slit lamp biomicroscopy to examine the anterior segment of the eye to exclude any corneal or lens abnormalities as corneal opacities, corneal dystrophy, corneal degeneration and/or cataract.

- Intraocular pressure measurement to exclude increasing IOP that may affect corneal biomechanics properties.
- Fundus examination: Dilated fundus examination to exclude any posterior segment disorder.

- Corneal topography using Oculus Pentacam for evaluation of corneal state (pachymetry, Kreading, anterior or posterior elevations.. etc).

- The Ocular Response Analyzer (ORA; Reichert Ophthalmic Instruments, Depew, NY, USA) to measure Corneal Hysteresis $(\mathrm{CH})$ and Corneal Resistance Factor (CRF).

\section{Results}

Table (1): Comparison between the two studied groups in preoperative $\mathrm{CH}, \mathrm{CRF}, \mathrm{CCT}$ and RSB.

\begin{tabular}{lllll}
\hline Variable & $\begin{array}{c}\text { LASIK } \\
\mathrm{n}=21\end{array}$ & $\begin{array}{l}\text { PRK } \\
\mathrm{n}=21\end{array}$ & $\begin{array}{c}t \text { - } \\
\text { test }\end{array}$ & $\begin{array}{c}p \text { - } \\
\text { value }\end{array}$ \\
\hline$C H:$ & & & & \\
$\quad$ Mean $\pm \mathrm{SD}$ & $10.5 \pm 1.2$ & $11 \pm 0.8$ & 1.4 & 0.1 \\
$\quad$ Range & $(8.8-12.6)$ & $(9.2-12.1)$ & & \\
$C R F:$ & & & & \\
$\quad$ Mean $\pm \mathrm{SD}$ & $10.9 \pm 1.5$ & $11.5 \pm 0.9$ & 1.5 & 0.1 \\
Range & $(8.6-13.2)$ & $(10.2-12.7)$ & & \\
$C C T:$ & & & & \\
Mean $\pm \mathrm{SD}$ & $558.4 \pm 22.1$ & $532.4 \pm 18.5$ & 1.9 & 0.08 \\
Range & $(524-587)$ & $(510-566)$ & & \\
$R S B:$ & & & & \\
$\quad \begin{array}{l}\text { Mean } \pm \mathrm{SD} \\
\text { Range }\end{array}$ & $403.7 \pm 21.8$ & $416.8 \pm 29.8$ & 1.6 & 0.1 \\
Median & $(369-431)$ & $(396-476)$ & & \\
\hline
\end{tabular}

Table (2): Comparing CH \& CRF before and after LASIK.

\begin{tabular}{lcccc}
\hline \multirow{2}{*}{ Variable } & Before & After & $t$-test & $p$-value \\
& LASIK & LASIK & & \\
\hline $\mathrm{CH}$ & $10.5 \pm 1.2$ & $8.2 \pm 1.5$ & 10.5 & 0.001 \\
$\mathrm{CRF}$ & $10.9 \pm 1.5$ & $8.6 \pm 2.1$ & 8.6 & 0.001 \\
\hline
\end{tabular}

Table (3): Comparing CH \& CRF before and after PRK.

\begin{tabular}{lcccc}
\hline Variable & $\begin{array}{c}\text { Before } \\
\text { PRK }\end{array}$ & $\begin{array}{c}\text { After } \\
\text { PRK }\end{array}$ & $t$-test & $p$-value \\
\hline $\mathrm{CH}$ & $11 \pm 0.8$ & $8.7 \pm 1.2$ & 7.9 & 0.001 \\
$\mathrm{CRF}$ & $11.5 \pm 0.9$ & $9.6 \pm 1.4$ & 6.8 & 0.001 \\
\hline
\end{tabular}

Table (4): Comparing SE before PRK and LASIK.

\begin{tabular}{lllll}
\hline Variable & $\begin{array}{l}\text { SE before } \\
\text { LASIK }\end{array}$ & $\begin{array}{c}\text { SE before } \\
\text { PRK }\end{array}$ & $t$-test & $p$-value \\
\hline Mean \pm SD & $-2.9 \pm 0.7$ & $-3.8 \pm 1$ & 3.4 & 0.001 \\
(Range) & -4.25 to -2.25 & -5.25 to -2.0 & & \\
Median & -2.7 & -4.2 & & \\
\hline
\end{tabular}


Table (5): Comparing between mean \pm SD of PRK and LASIK in percent of change in $\mathrm{CH}$ and $\mathrm{CRF}$.

\begin{tabular}{lcccc}
\hline Variable & LASIK & PRK & $t$-test & $p$-value \\
\hline CH & $0.23 \pm 0.08$ & $0.16 \pm 0.05$ & 3.1 & 0.004 \\
CRF & $0.24 \pm 0.07$ & $0.19 \pm 0.05$ & 2.1 & 0.030 \\
\hline
\end{tabular}

Table (6): Correlation between SE, CRF and CH after LASIK.

\begin{tabular}{llll}
\hline Variable & $r$ & \multicolumn{1}{c}{$p$} & Significance \\
\hline CH & -0.7 & 0.001 & HS \\
CRF & -0.6 & 0.001 & HS \\
RSB & 0.2 & $>0.05$ & NS \\
Age & -0.4 & 0.02 & S \\
\hline
\end{tabular}

Table (7): Correlation between SE, CRF and CH after PRK.

\begin{tabular}{llcc}
\hline Variable & $r$ & $p$ & Significance \\
\hline CH & -0.6 & 0.001 & HS \\
CRF & -0.4 & 0.001 & HS \\
RSB & 0.8 & 0.001 & HS \\
Age & 0.2 & $>0.05$ & NS \\
\hline
\end{tabular}

\section{Discussion}

The study subjects included 42 eyes with refractive error eligible for refractive surgery. They were divided into the following groups: Group (1): 21 myopic eyes undergoing Lasik surgery, 4 males (19\%) and 17 females (81\%) with age ranged from (27-38 years) and a mean age of $32 \pm 4.3$ years and group (2): 21 myopic eyes undergoing PRK surgery, 8 males $(38.1 \%)$ and 13 females $(61.9 \%)$ with age ranged from (23-42 years) and a mean age of 33.2 \pm 13.2 years, there was no statistically significant difference in age and sex between the two studied groups $(p>0.05)$, i.e. both groups were matched in age and sex.

Before operations both groups had a statistically non-significant difference in $\mathrm{CH}$ and CRF $(p>0.05)$. Also, there was no statistically significant difference in CCT and RSB between the studied groups $(p>0.05)$ at the beginning of the study. The study showed that there was a statistically very highly significant difference in $\mathrm{CH}$ and $\mathrm{CRF}$ before and after LASIK and PRK $(p<0.001)$. The study also showed that there was a statistically very highly significant difference in SE before and after LASIK and PRK $(p<0.001)$.

This study showed that there was statistically significant difference between LASIK and PRK in $\mathrm{CH}$ and CRF percent of change with more decrease after LASIK. So both Lasik and PRK are significantly decease $\mathrm{CH}$ and $\mathrm{CRF}$, however, Lasik decreases $\mathrm{CH}$ and $\mathrm{CRF}$ more than PRK.
These results was in parallel with Kamiya et al., [7] study which demonstrated that LASIK significantly decreased $\mathrm{CH}$ and $\mathrm{CRF}$ more than PRK, suggesting that LASIK could affect corneal biomechanics more than PRK. This may be due to the fact that LASIK requires both surgical tissue removal and flap creation, whereas PRK requires tissue removal only. In addition, LASIK ablates more of the deeper layers of the corneal stroma than PRK, which may contribute to the greater damage to the corneal nerves evident after LASIK because these are transected at a deeper plane of the cornea.

The study also showed that there was a statistically highly significant negative correlation between SE, CRF and CH $(p<0.01)$, and a statistically significant correlation with age $(p<0.05)$ and there were a statistically non-significant correlation with RSB in patients with LASIK, while there was a statistically highly significant negative correlation between SE, CRF, CH and RSB in patients with PRK $(p<0.01)$, while there was a statistically nonsignificant difference with age $(p>0.05)$.

Corneas with ectasia are thought to have biomechanical properties that predispose them to a cone shape. Lower CH and CRF have been demonstrated in forme fruste keratoconus and keratoconus [8] and the waveform morphology on ORA of corneas with post-LASIK ectasia differs from non-ectatic corneas [9].

LASIK is thought to be more likely to cause post-operative corneal ectasia since the treatment occurs deeper in the corneal stroma than PRK [10]

Accordingly, a greater decrease in corneal biomechanical properties with LASIK than with PRK might be expected. This hypothesis was supported by a retrospective study of LASIK (31 eyes) and PRK without MMC (27 eyes) by Kamiya et al. [7], which found a greater decrease in corneal biomechanical properties after LASIK.

In contrast, most recently, Hwang et al., [1] studied the biomechanical properties of 230 eyes after LASIK and 115 eyes after PRK without MMC and found similar decreases after both procedures. The lack of a significant difference between the two procedures likely indicates similar long-term effects on corneal biomechanical properties by LASIK and PRK without MMC.

In contrast to the stability of $\mathrm{CH}$ and $\mathrm{CRF}$ measurements after LASIK and PRK without MMC, it was found that after PRK with MMC, there was a small decrease in the first 3 months 
and then a proportionate increase from 3 to 12 months. Thus, at 12 months, $\mathrm{CRF}$ and $\mathrm{CH}$ values were similar for all three procedures [1]. Another group compared PRK with MMC and LASIK in the fellow eye and found lower postoperative CRF and $\mathrm{CH}$ values at 12 months in the LASIK group [11].

This study did not report earlier time points, so the changes in $\mathrm{CH}$ and $\mathrm{CRF}$ in the immediate post-operative time period are unknown for their patients. Hwang et al., [1] randomized study had a larger sample size compared to our study, whereas our study had relatively few patients undergoing PRK with MMC.

The main advantage of Hwang et al., [1] study is the large cohort of patients with 3-month, 6month and 12-month measurements of $\mathrm{CH}$ and CRF after LASIK and PRK with and without MMC. However, a weakness of their study is that the patients were not randomized and the treatment groups differed in baseline refractive error, CCT, $\mathrm{CRF}$, and $\mathrm{CH}$. In routine clinical care, patients who receive PRK differ from those who receive LASIK.

Corneal ectasia following refractive surgery is a complication that all surgeons wish to avoid. Many pre-operative guidelines to assess ectasia risk have been published [12]

Corneal measurements by ORA may add to this arsenal and help in identifying patients susceptible to ectasia. Our study specifically examined the effects of LASIK and PRK on CH and CRF. Significant but similar decreases in corneal biomechanical properties after LASIK, PRK without MMC, and PRK with MMC were noted. This may suggest that the type of procedure is not as important as the native characteristics of the patient's cornea in determining the risk for ectasia. The role of $\mathrm{CH}$ and $\mathrm{CRF}$ measurements in refractive surgery patients is still being elucidated, and further studies will help clarify the relationship of these values with the risk of ectasia [1]

In the Kamiya et al., [7] study, demonstrated that both keratorefractive surgical procedures reduced $\mathrm{CH}$ and CRF depending on the amount of myopic correction, indicating that both keratorefractive techniques can affect the biomechanical parameters of the cornea, especially when a large amount of laser ablation is required in highly myopic eyes. These findings may be supported by the fact that iatrogenic keratectasia tended to occur in eyes with high myopia [13].
Seiler et al., [14] reported that the residual corneal bed thickness was critical for determining the mechanical strength of the cornea after LASIK. These findings are also confirmed by the fact that as many as $26 \%$ of patients developed iatrogenic keratoconus after hyperopic automated lamellar keratoplasty, which intentionally attempts deeper tissue dissection [15].

Unfortunately, intraoperative pachymetry didn't performed in this study. Kamiya et al., [7] usually performed it only in eyes with high myopia or with a thin cornea, and they recommended phakic intraocular lens implantation in such eyes to avoid the theoretical risk of keratectasia. They previously evaluated flap thickness in 26 eyes using intraoperative pachymetry, demonstrating that mean flap thickness was $127.5 \pm 11.9$ (SD) $\mathrm{mm}$ (range, 108 to $149 \mathrm{~mm}$ ), and this indicated that flap thickness measurement with an LSK-1 microkeratome was reproducible. However, it has been reported that the anterior flap thickness may appear to vary considerably because of microkeratome inaccuracy [16].

The creation of a thick flap and the photoablation of deep stroma may have contributed to the greater decreases in corneal biomechanics after LASIK. Intraoperative pachymetry may provide us further information about biomechanical changes in the cornea [7]. Although it's accepted that some biomechanical factors might have played a role, such as the integrity of Bowman's membrane, the epithelial wound healing process, or long-term usage of steroid eye drops, PRK may be a safer surgical option for biomechanically weaker eyes such as those with a thin cornea or those requiring enhancement surgery to avoid the possible risk of keratectasia.

On the other hand, Kirwan and O'Keefe [17] reported that the decrease in $\mathrm{CH}$ was not statistically different after LASIK and laser-assisted subepithelial keratectomy (LASEK), indicating that LASIK involving a thin 90- did not induce additional biomechanical change. The intended flap thickness and the amount of myopic correction in our study are larger than those in their study. The differences of surgical technique (PRK vs. LASEK), flap thickness (130 amount of myopic correction (LASIK, $4.1 \pm 1.6 \mathrm{D}$; PRK, $4.1 \pm 1.5 \mathrm{D}$ vs. LASIK, $3.8 \pm 1.5 \mathrm{D}$; LASEK, $3.3 \pm 1.9 \mathrm{D})$ may account for this discrepancy. Further studies are necessary for clarifying this point.

It is clinically important to assess the postoperative biomechanical changes of the cornea in 
light of the increasing number of reports of iatrogenic keratectasia after excimer laser keratorefractive surgery. The Ocular Response Analyzer (Reichert Ophthalmic Instruments, Depew, NY) has been developed to assess the biomechanical properties of the cornea [2].

Kamiya et al., [7] study show that the mean difference between two consecutive measurements with ORA was $-0.1 \pm 0.5 \mathrm{mmHg}$ ( -1.1 to $1.0 \mathrm{mmHg}$ ) for $\mathrm{CH}$, and $0.0 \pm 0.5 \mathrm{mmHg}(-0.9$ to $1.0 \mathrm{mmHg}$ ) for CRF. Moreover, Lu et al., [18] reported that the repeatability of the $\mathrm{CH}$ was $0.8 \mathrm{mmHg}$ as the standard deviation of the differences between two measurements. Therefore, we believe that this device (ORA) offers reasonable repeatability in the evaluation of the biomechanical properties of the cornea.

Although it is accepted that a randomized controlled study is desirable for confirming the authenticity of the results, it is believed that this comparison is clinically acceptable for the assessment of the post-operative biomechanical changes after two surgical procedures. Other limitations are that the sample data were comparatively small in amount and that the follow-up time was short. The post-operative $\mathrm{CH}$ and CRF were measured at 3 months after surgery, when the biomechanical properties of the cornea were considered to have been stabilized, taking into account the woundhealing responses of the cornea. However, in light of reports of delayed-onset keratectasia [19], we cannot deny the possibility that biomechanical changes may be ongoing throughout the long-term periods. Further observation is needed to elucidate the long-term biomechanical changes of the cornea.

In conclusion, this preliminarily results demonstrate that both PRK and LASIK substantially weaken the biomechanical strength of the cornea, depending on the amount of archived myopic correction, and that the changes in corneal biomechanics were larger after LASIK than after PRK. These findings indicate that PRK, which requires only surgical tissue removal, may be biomechanically a less invasive approach than LASIK, which requires not only deeper tissue ablation but also the creation of a thick flap, although the inferiority of LASIK in this study may have resulted from the creation of a thicker flap.

\section{References}

1- HWANG E.S., STAGG B.C., SWAN R., FENZL C.R., McFADDEN M., MUTHAPPAN V., SANTIAGOCABAN L., MIFFLIN M.D. and MOSHIRFAR M.: Corneal biomechanical properties after laser-assisted in situ keratomileusis and photorefractive keratectomy. Clin. Ophthalmol., 11: 1785-9, 2017.

2- LUCE D.A.: Determining in vivo biomechanical properties of the cornea with an ocular response analyzer. J. Cataract. Refract. Surg., 31: 156-62, 2005.

3- KOTECHA A.: What biomechanical properties of the cornea are relevant for the clinician? Surv. Ophthalmol., 52 (Suppl 2): 109-14, 2007.

4- ROSA N., LANZA M., De BERNARDO M., SIGNORIELLO G. and CHIODINI P.: Relationship between corneal hysteresis and corneal resistance factor with other ocular parameters. Semin Ophthalmol., 30 (5-6): 335-9, 2015.

5- HASHEMI H., MIRAFTAB M. and ASGARI S.: Photorefractive keratectomy results in myopic patients with thin cornea eyes. Oman J. Ophthalmol., 8 (1): 24-7, 2015.

6- WANG B., ZHANG Z., NAIDU R.K., et al.: Comparison of the change in posterior corneal elevation and corneal biomechanical parameters after small incision lenticule extraction and femtosecond laser-assisted LASIK for high myopia correction. Cont. Lens. Anterior. Eye, 39 (3): 191-6, 2016.

7- KAMIYA K., SHIMIZU K. and OHMOTO F.: Comparison of the changes in corneal biomechanical properties after photorefractive keratectomy and laser in situ keratomileusis. Cornea, 28 (7): 765-9, 2009.

8- JOHNSON R.D., NGUYEN M.T., LEE N. and HAMILTON D.R.: Corneal biomechanical properties in normal, forme fruste keratoconus, and manifest keratoconus after statistical correction for potentially confounding factors. Cornea, 30 (5): 516-23, 2011.

9- KERAUTRET J., COLIN J., TOUBOUL D. and ROBERTS C.: Biomechanical characteristics of the ectatic cornea. J. Cataract. Refract. Surg., 34: 510-3, 2008.

10- RANDLEMAN J.B., CASTER A.I., BANNING C.S. and STULTING R.D.: Corneal ectasia after photorefractive keratectomy. J. Cataract. Refract. Surg., 32: 1395-8, 2006.

11- WALLAU A.D. and CAMPOS M.: One-year outcomes of a bilateral randomised prospective clinical trial comparing PRK with mitomycin C and LASIK. Br. J. Ophthalmol., 93: 1634-8, 2009.

12- FONTES B.M., AMBRÓSIO R., JARDIM D., VELARDE G.C. and NOSÉ W.: Corneal biomechanical metrics and anterior segment parameters in mild keratoconus. Ophthalmology, 117 (4): 673-9, 2010.

13- RANDLEMAN J.B.: Post-laser in-situ keratomileusis ectasia: Current understanding and future directions. Curr. Opin. Ophthalmol., 17: 406-12, 2006.

14- SEILER T., KOUFALA K. and RICHTER G.: Iatrogenic keratectasia after laser in situ keratomileusis. J. Refract. Surg., 14: 312-7, 1998.

15- LYLE W.A. and JIN G.J.: Hyperopic automated lamellar keratoplasty: Complications and visual results. Arch. Ophthalmol., 116: 425-8, 1998.

16- BEHRENS A., LANGENBUCHER A., KUS M.M., et al.: Experimental evaluation of two current-generation automated microkeratomes: The Hansatome and the $\mathrm{Su}-$ pratome. Am. J. Ophthalmol., 129: 59-67, 2000.

17- KIRWAN C. and O'KEEFE M.: Corneal hysteresis using the Reichert ocular response analyser: Findings pre-and 
post-LASIK and LASEK. Acta Ophthalmol., 86 (2): 215 8, 2008.

18- LU F., XU S., QU J., SHEN M., WANG X., FANG H. and WANG J.: Central corneal thickness and corneal hysteresis during corneal swelling induced by contact lens wear with eye closure. Am. J. Ophthalmol., 143 (4): 616-22, 2007

19- LIFSHITZ T., LEVY J., KLEMPERER I., et al.: Late bilateral keratectasia after LASIK in a low myopic patient. J. Refract. Surg., 21: 494-6, 2005.

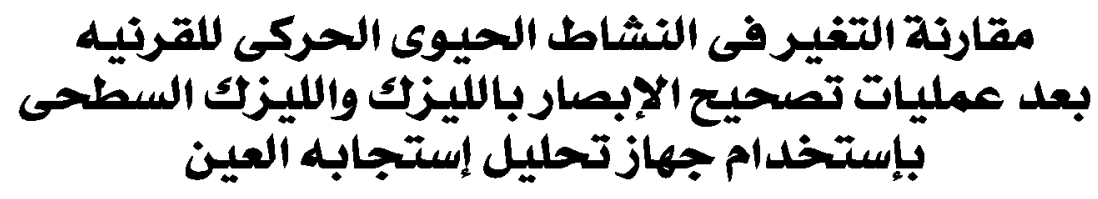

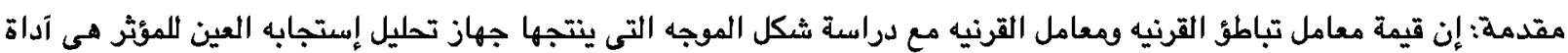

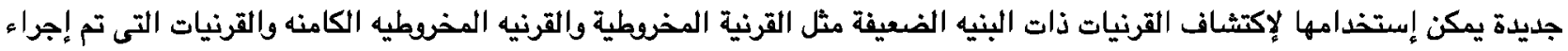

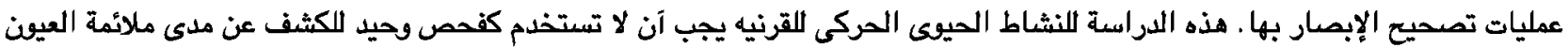
لعمليات تصحيح الإبصار لكن كجهاز مساعد اللفحوصات الطوبيوغرافية والإكلينيكية.

الهدف من البحث: مقارنة التغير فالنثاط الحيوى الحركى للقرنيه بعد عملية تصحيح الإبصار بالليزك والليزك السطحى فى علاج قصر النظر بإستخدام جهاز محلل إستجابه العين.

النتائج والتوصيات: نستنتج من هذه الدراسة آن مرونة القرنية التى يعبر عنها (معامل تباطؤ القرنيه ومعامل مقاومة القرنية) والتى تقاس

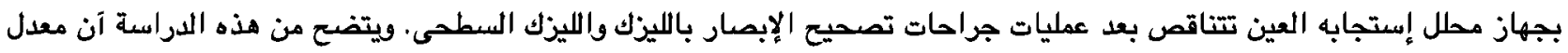

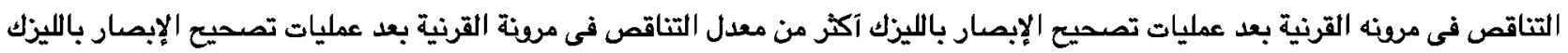

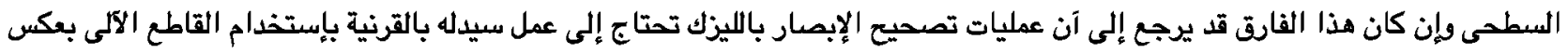

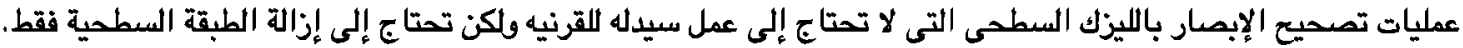

